\title{
Ventilação mecânica: princípios, análise gráfica e modalidades ventilatórias
}

\author{
Carlos Roberto Ribeiro de Carvalho, Carlos Toufen Junior, Suelene Aires Franca
}

\section{Princípios da ventilação mecânica}

\section{Definição}

A ventilação mecânica (VM) ou, como seria mais adequado chamarmos, o suporte ventilatório, consiste em um método de suporte para o tratamento de pacientes com insuficiência respiratória aguda ou crônica agudizada.

\section{Objetivos}

Tem por objetivos, além da manutenção das trocas gasosas, ou seja, correção da hipoxemia e da acidose respiratória associada à hipercapnia: aliviar o trabalho da musculatura respiratória que, em situações agudas de alta demanda metabólica, está elevado; reverter ou evitar a fadiga da musculatura respiratória; diminuir o consumo de oxigênio, dessa forma reduzindo o desconforto respiratório; e permitir a aplicação de terapêuticas específicas.

\section{Classificação}

Atualmente, classifica-se o suporte ventilatório em dois grandes grupos:

- Ventilação mecânica invasiva; e

- Ventilação não invasiva.

Nas duas situações, a ventilação artificial é conseguida com a aplicação de pressão positiva nas vias aéreas. A diferença entre elas fica na forma de liberação de pressão: enquanto na ventilação invasiva utiliza-se uma prótese introduzida na via aérea, isto é, um tubo oro ou nasotraqueal (menos comum) ou uma cânula de traqueostomia, na ventilação não invasiva, utiliza-se uma máscara como interface entre o paciente e o ventilador artificial.

\section{Princípios}

A ventilação mecânica (VM) se faz através da utilização de aparelhos que, intermitentemente, insuflam as vias respiratórias com volumes de ar (volume corrente - VT). 0 movimento do gás para dentro dos pulmões ocorre devido à geração de um gradiente de pressão entre as vias aéreas superiores e o alvéolo, podendo ser conseguido por um equipamento que diminua a pressão alveolar (ventilação por pressão negativa) ou que aumente a pressão da via aérea proximal (ventilação por pressão positiva). Devido à sua maior aplicação na prática clínica, vão ser comentados somente os aspectos relacionados à ventilação com pressão positiva, tanto na forma invasiva como na não invasiva. Neste ar, controla-se a concentração de $\mathrm{O}_{2}\left(\mathrm{FlO}_{2}\right)$ necessária para obter-se uma taxa arterial de oxigênio (pressão parcial de oxigênio no sangue arterial- $\mathrm{PaO}_{2}$ ) adequada. Controlase ainda, a velocidade com que o ar será administrado (fluxo inspiratório - $\dot{V}$ ) e também se define a forma da onda de fluxo, por exemplo, na ventilação com volume controlado: "descendente", "quadrada" (mantém um fluxo constante durante toda a inspiração), "ascendente" ou "sinusoidal". 0 número de ciclos respiratórios que os pacientes realizam em um minuto (freqüência respiratória - f) será conseqüência do tempo inspiratório (Tl), que depende do fluxo, e do tempo expiratório (TE). 0 TE pode ser definido tanto pelo paciente (ventilação assistida), de acordo com suas necessidades metabólicas, como através de programação prévia do aparelho (ventilação controlada). 0 produto da f pelo VT é o volume minuto (VE). Dessa forma, fica claro o que acontece quando fazemos ajustes no aparelho. Por exemplo, se optarmos por ventilar um paciente em volume assistido/ controlado, o que temos que definir para o ventilador é o VT e o $\dot{V}$ e, de acordo com a resistência e a complacência do sistema respiratório do paciente, uma determinada pressão será atingida na via aérea. Se, por outro lado, trabalharmos com um ventilador que cicla em pressão, temos que calibrar o pico de pressão inspiratória (PPI) e o $\dot{\mathrm{V}}$, sendo o VT uma conseqüência dessa forma de ventilação. Esse tipo de ventilação (ciclada à pressão) que, praticamente, não é mais aplicada está presente em ventiladores do tipo Bird Mark $7^{\circledR}$.

\section{Indicações}

Os critérios para aplicação de VM variam de acordo com os objetivos que se quer alcançar. Em situações de urgência, especialmente quando o risco de vida não permite boa avaliação da função respiratória, a impressão clínica 
é o ponto mais importante na indicação de VM, auxiliada por alguns parâmetros de laboratório (Tabela 1).

As principais indicações para iniciar o suporte ventilatório são:

- Reanimação devido à parada cardiorrespiratória;

- Hipoventilação e apnéia: A elevação na $\mathrm{PaCO}_{2}$ (com acidose respiratória) indica que está ocorrendo hipoventilação alveolar, seja de forma aguda, como em pacientes com lesões no centro respiratório, intoxicação ou abuso de drogas e na embolia pulmonar, ou crônica nos pacientes portadores de doenças com limitação crônica ao fluxo aéreo em fase de agudização e na obesidade mórbida;

- Insuficiência respiratória devido a doença pulmonar intrínseca e hipoxemia. Diminuição da $\mathrm{PaO}_{2}$ resultado das alterações da ventilação/ perfusão (até sua expressão mais grave, o shunt intrapulmonar). A concentração de hemoglobina $(\mathrm{Hb})$, o débito cardíaco (DC), o conteúdo arterial de oxigênio $\left(\mathrm{CaO}_{2}\right)$ e as variações do $\mathrm{pH}$ sangüíneo são alguns fatores que devem ser considerados quando se avalia o estado de oxigenação arterial e sua influência na oxigenação tecidual;

- Falência mecânica do aparelho respiratório:

- Fraqueza muscular / Doenças neuromusculares / Paralisia; e

- Comando respiratório instável (trauma craniano, acidente vascular cerebral, intoxicação exógena e abuso de drogas).

Tabela 1 - Parâmetros que podem indicar a necessidade de suporte ventlatório.

\begin{tabular}{|c|c|c|}
\hline Parâmetros & Normal & $\begin{array}{c}\text { Considerar } \\
\text { VM }\end{array}$ \\
\hline Freqüência respiratória & $12-20$ & $>35$ \\
\hline Volume corrente $(\mathrm{mL} / \mathrm{kg})$ & $5-8$ & $<5$ \\
\hline Capacidade Vital (mL/kg) & $65-75$ & $<50$ \\
\hline Volume minuto (L/min) & $5-6$ & $>10$ \\
\hline Pressão inspiratória máxima $\left(\mathrm{cmH}_{2} \mathrm{O}\right)$ & $80-120$ & $>-25$ \\
\hline Pressão expiratória máxima $\left(\mathrm{cmH}_{2} 0\right)$ & $80-100$ & $<+25$ \\
\hline Espaço morto $(\%)$ & $25-40$ & $>60$ \\
\hline $\mathrm{PaCO}_{2}(\mathrm{mmHg})$ & $35-45$ & $>50$ \\
\hline $\mathrm{PaO}_{2}(\mathrm{mmHg})\left(\mathrm{FlO}_{2}=0,21\right)$ & $>75$ & $<50$ \\
\hline $\mathrm{P}(\mathrm{A}-\mathrm{a}) \mathrm{O}_{2}\left(\mathrm{FlO}_{2}=1,0\right)$ & $25-80$ & $>350$ \\
\hline $\mathrm{PaO}_{2} / \mathrm{FlO}_{2}$ & $>300$ & $<200$ \\
\hline
\end{tabular}

- Prevenção de complicações respiratórias:

- Restabelecimento no pós-operatório de cirurgia de abdome superior, torácica de grande porte, deformidade torácica, obesidade mórbida; e

- Parede torácica instável.

- Redução do trabalho muscular respiratório e fadiga muscular. Um aumento no volume minuto através da elevação da $f$, com conseqüente diminuição no VT, é o mecanismo de adaptação transitório que se não for revertido levará à fadiga muscular devido ao aumento da demanda metabólica, aumento da resistência e/ou diminuição da complacência do sistema respiratório, fatores obstrutivos intrabrônquicos, restrição pulmonar, alteração na parede torácica, elevação da pressão intraabdominal, dor, distúrbios neuromusculares e aumento do espaço morto.

Resumindo, a VM é aplicada em várias situações clínicas em que o paciente desenvolve insuficiência respiratória, sendo, dessa forma, incapaz de manter valores adequados de $\mathrm{O}_{2}$ e $\mathrm{CO}_{2}$ sangüíneos, determinando um gradiente (ou diferença) alvéolo-arterial de $\mathrm{O}_{2}\left[(\mathrm{PA}-\mathrm{a}) \mathrm{O}_{2}\right.$ ] e outros indicadores da eficiência das trocas gasosas (por exemplo: relação $\mathrm{PaO}_{2} / \mathrm{FlO}_{2}$ ) alterados. Hipoxemia com gradiente aumentado indica defeito nas trocas alvéolo-capilares (insuficiência respiratória hipoxêmica). Hipoxemia com gradiente normal é compatível com hipoxemia por hipoventilação alveolar (insuficiência respiratória ventilatória). Sob oxigenoterapia e/ou ventilação mecânica, a relação $\mathrm{PaO}_{2} / \mathrm{FlO}_{2}$ tem sido usada na quantificação da gravidade da lesão pulmonar, na comparação evolutiva e na predição das mudanças na $\mathrm{PaO}_{2}$ se a $\mathrm{FlO}_{2}$ for elevada. 0 valor normal em ar ambiente é acima de 300, valores abaixo indicam deterioração de trocas e menor do que 200 sugerem extrema gravidade do quadro respiratório. $\mathrm{Na}$ insuficiência respiratória, o suporte ventilatório consegue contrabalançar esses defeitos, permitindo uma melhor relação ventilação/perfusão capilar (resultando em melhor $\mathrm{PaO}_{2}$ ), aumenta a ventilação alveolar (melhor $\mathrm{pH}$ e $\mathrm{PaCO}_{2}$ ), aumenta o volume pulmonar prevenindo ou tratando as atelectasias, otimiza a capacidade residual pulmonar-CRF, reduz o trabalho muscular respiratório com diminuição do consumo de $\mathrm{O}_{2}$ sistêmico e miocárdico, diminui a pressão intracraniana e estabiliza a parede torácica. 
Assim, o princípio do ventilador mecânico é gerar um fluxo de gás que produza determinada variação de volume com variação de pressão associada. As variações possiveis para esta liberação de fluxo são enormes e, com o progresso dos ventiladores microprocessados, as formas de visualizar e controlar o fluxo, o volume e a pressão estão em constante aprimoramento. Cada vez mais a equipe da UTl estará exposta a diferentes formas de apresentação e análise de parâmetros respiratórios fornecidas pelo ventilador, sofisticando as decisões clínicas. Nosso objetivo é apresentar e padronizar os conceitos e as modalidades ventilatórias que serão discutidas ao longo deste Consenso.

Atualmente, a maior parte dos ventiladores artificiais apresenta telas nas quais se podem visualizar as curvas de volume, fluxo e pressão ao longo do tempo, assim, serão apresentadas, neste capítulo, as definições das modalidades ventilatórias usando esquemas representativos das curvas.

\section{O ciclo ventilatório}

0 ciclo ventilatório durante a ventilação mecânica com pressão positiva pode ser dividido em (Figura 1):

1) Fase inspiratória: Corresponde à fase do ciclo em que o ventilador realiza a insuflação pulmonar, conforme as propriedades elásticas e resistivas do sistema respiratório. Válvula inspiratória aberta;

2) Mudança de fase (ciclagem): Transição entre a fase inspiratória e a fase expiratória;

3) Fase expiratória: Momento seguinte ao fechamento da válvula inspiratória e abertura da válvula expiratória, permitindo que a pressão do sistema respiratório equilibre-se com a pressão expiratória final determinada no ventilador; e

Curva de fluxo - Ventilação controlada por volume

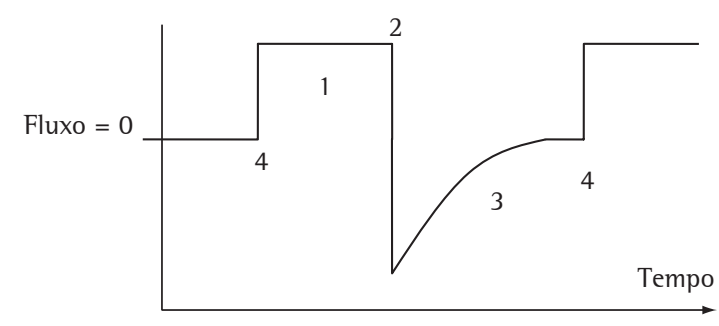

Figura 1 - Fases do ciclo ventilatório.
4) Mudança da fase expiratória para a fase inspiratória (disparo): Fase em que termina a expiração e ocorre o disparo (abertura da válvula ins) do ventilador, iniciando nova fase inspiratória.

\section{Análise gráfica durante a ventilação mecânica}

\section{Curvas de fluxo}

0 fluxo geralmente é medido diretamente pelo ventilador, através de sensores de pressão diferencial que estão posicionados entre a cânula endotraqueal e o " $Y$ " do circuito do ventilador. 0 fluxo inicia-se, nos modos controlados, depois de determinado intervalo de tempo (depende da $f$ ou da relação inspiração:expiração - Tl/TE) ou através de um limite de sensibilidade (trigger ou disparo) pré-estabelecido. Duas técnicas são utilizadas na prática para o disparo de um ciclo ventilatório: a queda de pressão ou a geração de fluxo (na modalidade assistida e/ou espontânea). Após o início do ciclo (disparo) o fluxo aumenta até atingir um valor pré-fixado, chamado de pico de fluxo. Este valor é definido pelo operador no modo volume controlado e pode ser mantido constante ou ter valor decrescente no tempo. 0 fluxo, nessa modalidade, vai definir o tempo que a válvula inspiratória permanecerá aberta (TI), de acordo com o VT estabelecido. Por exemplo: Ventilação com volume controlado com VT de $500 \mathrm{~mL}$ e $\dot{\mathrm{V}}$ de $60 \mathrm{~L} / \mathrm{min}$ (ou seja, $1 \mathrm{~L} / \mathrm{s}$ ); logo o Tl será de $0,5 \mathrm{~s}$ - tempo que a válvula inspiratória permanecerá aberta para propiciar a entrada de $1 / 2 \mathrm{~L}$ de ar. 0 fluxo inspiratório encerra-se conforme o modo de ciclagem estabelecido, ou seja, fecha-se a válvula ins e abre-se a válvula expiratória do aparelho, começando então o fluxo expiratório. As características da curva de fluxo nos modos espontâneos (pico e duração) são determinadas pela demanda do paciente. 0 começo e o final da inspiração são, normalmente, minimamente afetados pelo tempo de resposta do sistema de demanda (válvulas). Porém, em casos de alta demanda (por parte do paciente), o retardo na abertura da válvula inspiratória pode gerar dissincronia paciente-ventilador. Na Figura 2 abaixo, apresentamos o exemplo de uma onda de fluxo quadrada (fluxo constante) no modo volume controlado. Apresentamos ainda a característica da onda de fluxo na ventilação espontânea sem o uso de suporte ventilatório. 


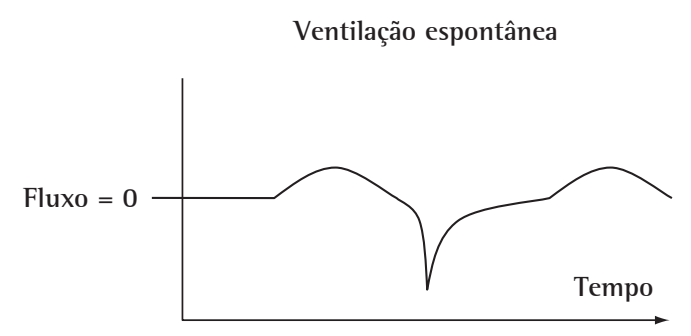

Ventilação controlada por volume

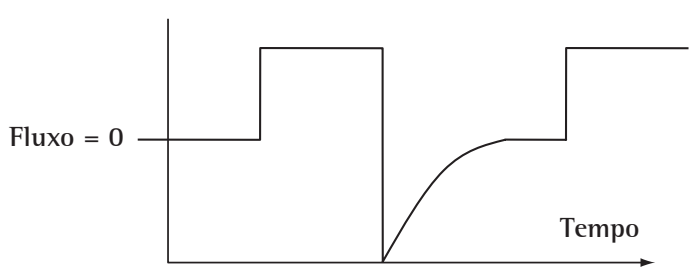

Figura 2 - Curvas de fluxo.

A forma da onda de fluxo pode ser modificada no ventilador diretamente ou indiretamente conforme o modo ventilatório escolhido. Abaixo, alguns exemplos de curva de fluxo (Figura 3).

As formas mais utilizadas na prática clínica são a quadrada, permite a realização da monitoração da mecânica respiratória, e a descendente, proporciona uma melhor distribuição do ar inspirado.

\section{Curvas de pressão}

A pressão é geralmente medida pelo ventilador diretamente, através de transdutor instalado próximo ao tubo endotraqueal ("Y" do circuito do ventilador).

Durante a ventilação espontânea, na inspiração, devido à contração da musculatura respiratória, ocorre uma queda da pressão nos alvéolos/vias aéreas para que seja gerado o fluxo inspiratório (Figura 2). $\mathrm{Na}$ ventilação assistida e em modos espontâneos como a Pressão de Suporte, a contração da musculatura vai depender da demanda metabólica do paciente (controle neural - drive), vai proporcionar a queda de pressão no circuito e, de acordo com

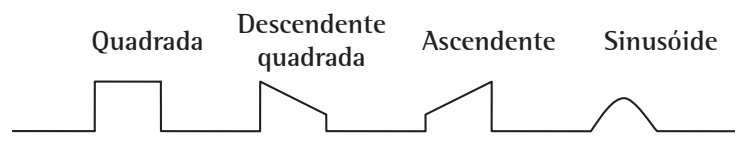

Figura 3 - Formas da curva de fluxo. a sensibilidade ajustada, promover a abertura da válvula (disparo) gerando um pico de fluxo inspiratório, aumentando progressivamente a pressão no sistema respiratório do paciente. Na expiração, ao contrário, como a pressão no sistema está elevada, a abertura da válvula expiratória promoverá a saída passiva do VT.

No gráfico abaixo, Figura 4, o traçado de pressão nas vias aéreas começa e termina no nível zero. Entretanto, é possível utilizar uma pressão positiva ao final da expiração (PEEP, do inglês positive end expiratory pressure), quando, então, o traçado partirá e terminará em um nível de pressão acima de zero. Note que na ventilação espontânea a pressão intratorácica é negativa na ins e positiva na expiração, enquanto que durante a ventilação mecânica, a pressão nas vias aéreas se mantém positiva durante todo o ciclo (desde que se use uma PEEP). Esse fato gera repercussões hemodinâmicas que devem ser do conhecimento do profissional responsável pelo suporte ventilatório do paciente.

Componentes da pressão inspiratória: Como observado no gráfico da Figura 4, à medida que o fluxo de ar adentra o sistema respiratório, a pressão inspiratória vai se elevando, pois é necessária para vencer dois componentes: um resistivo (devido à resistência ao fluxo de ar passando pelas vias aéreas) e outro elástico (decorrente da distensão dos

Ventilação espontânea

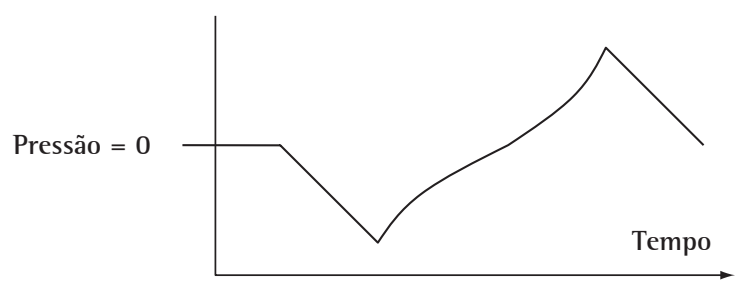

Ventilação controlada por volume

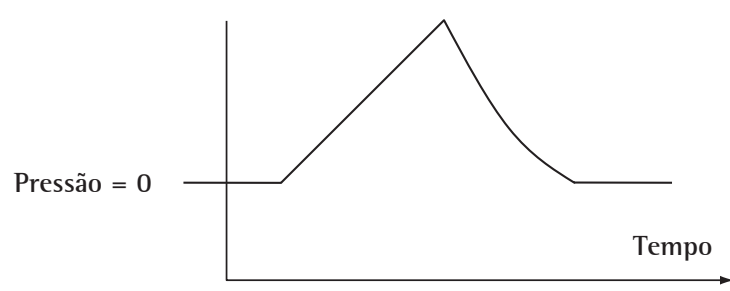

Figura 4 - Curvas de pressão nas vias aéreas. 
pulmões e da parede torácica). Estes dois componentes são demonstrados abaixo, quando um determinado volume é fornecido com fluxo constante até determinado ponto (1), quando ocorre uma interrupção do fluxo (pausa inspiratória) que determina a pressão de platô (2), Figura 5.

0 ponto (1) representa o pico de pressão (PPI) nas vias aéreas, que sofre interferência tanto do fluxo (Pres $=$ pressão resistiva) como da variação de volume $(\mathrm{Pel}=$ pressão elástica). Já o ponto (2) marca a pressão de platô (PPLATÔ) das vias aéreas, que representa a pressão de equilíbrio do sistema respiratório, na ausência de fluxo (não existe fluxo, portanto não há o componente de resistência das vias aéreas).

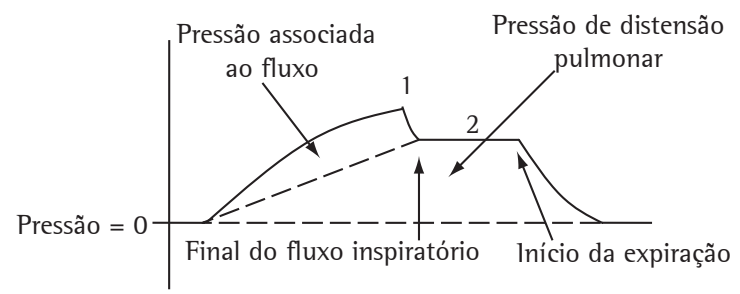

$\mathrm{PPl}=$ Pres + Pel

Pres $=\mathrm{R} \times \mathrm{V}^{\prime}$ (ou seja, produto da resistência pelo fluxo) $\mathrm{Pel}=$ VT $/$ C (ou seja, divisão do VT pela complacência)

Figura 5 - Componentes da pressão Inspiratória.
Na situação de fluxo zero (pausa inspiratória), observa-se que a Pel corresponde à pressão no sistema que equilibrou aquele volume de ar que entrou (VT), portanto sua relação é a complacência do sistema respiratório. Pois, na situação de fluxo zero, a pressão resistiva é zero e a pressão observada no sistema (pressão de platô), corresponde à pressão elástica do sistema respiratório (diferença entre a PPLATÔ e a PEEP).

\section{Disparo do ventilador}

Durante a ventilação mecânica, uma variável de disparo pré-determinada deve ser alcançada para iniciar a inspiração. Com a ventilação controlada, a variável é o tempo e é independente do esforço do paciente. Nos modos que permitem ciclos assistidos e espontâneos, a inspiração começa quando se alcança um nível de pressão ou fluxo pré-determinado (sensibilidade).

No disparo à pressão, o ventilador detecta uma queda na pressão de vias aéreas ocasionada pelo esforço do paciente. Este esforço pode iniciar a inspiração se a pressão negativa realizada ultrapassar o limiar de pressão para o disparo (sensibilidade ou trigger) ou pode não disparar o ciclo, caso a pressão negativa não ultrapasse este limiar, gerando apenas trabalho respiratório e dissincronia (Figura 6). 0

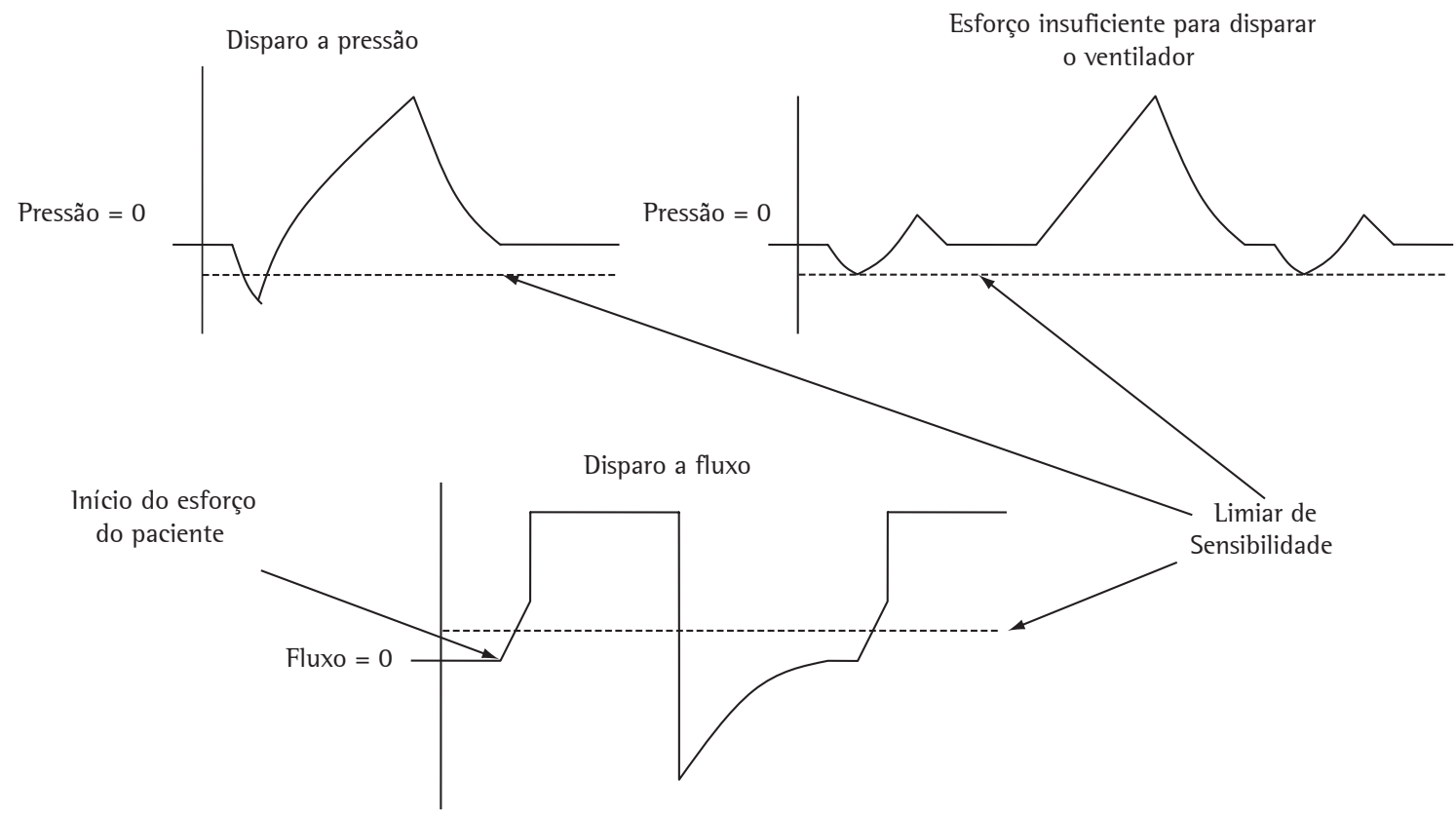

Figura 6 - Disparo do ventilador por pressão e fluxo. 
limiar de pressão é determinado pelo operador no ventilador, que indicará sempre a pressão negativa abaixo da PEEP necessária para disparar o ventilador. 0 disparo a fluxo envolve o uso de um fluxo inspiratório basal contínuo (bias flow ou continuous flow). Quando a diferença entre o fluxo inspiratório e o fluxo expiratório alcançar um determinado limite de sensibilidade, abre-se a válvula ins e um novo ciclo ventilatório começa.

Sensibilidade e tempo de resposta do ventilador: Quando o disparo é determinado pelo paciente existe um intervalo entre o início da deflexão negativa da pressão e o início do fluxo inspiratório. A este intervalo chamamos de "tempo de resposta do ventilador". Este tempo depende da sensibilidade da válvula inspiratória do ventilador e da capacidade do ventilador em gerar o fluxo (Figura 7). Quando o tempo de resposta do ventilador é elevado, o paciente fará um esforço acima do necessário até que o fluxo se inicie, aumentando o trabalho respiratório e gerando dissincronia paciente-ventilador. Em geral admite-se como responsividade aceitável aquela abaixo de 150 milissegundos.

\section{Curvas de volume}

0 gráfico de volume representa, em sua porção ascendente, o volume pulmonar inspirado e, em sua curva descendente, o volume pulmonar total expirado. Os volumes são iguais a menos que esteja ocorrendo vazamento, desconexão do circuito ou aprisionamento aéreo (Figura 8).

\section{Curvas de fluxo, pressão e volume em função do tempo}

Individualmente, as curvas de fluxo, pressão e volume são importantes, porém podemos utilizar

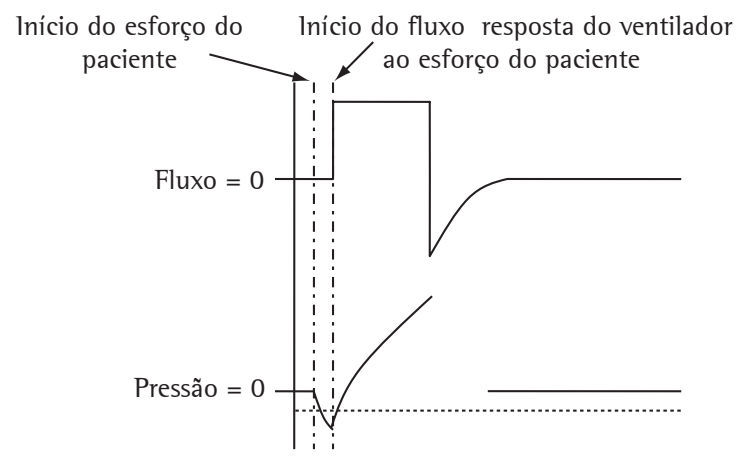

Figura 7 - Sensibilidade e responsividade. e completar melhor as curvas quando estão associadas. Abaixo, na Figura 9, são mostradas as três formas de curvas em associação, durante a ventilação controlada, assistida e espontânea.

\section{Modalidades ventilatórias convencionais}

\section{Ventilação mandatória contínua}

Todos os ciclos ventilatórios são disparados e/ ou ciclados pelo ventilador (ciclos mandatórios). Quando o disparo ocorre pelo tempo, o modo é apenas controlado. Quando o disparo ocorre de acordo com pressão negativa ou fluxo positivo realizados pelo paciente, chamamos o modo de assistido/controlado.

Nos ventiladores mecânicos mais modernos, a ventilação mandatória contínua pode ocorrer com volume controlado (os ciclos mandatórios têm como variável de controle o volume, são limitados a fluxo e ciclados a volume) ou com pressão controlada (os ciclos mandatórios têm como variável de controle a pressão, são limitados a pressão e ciclados a tempo).

\section{Ventilação mandatória contínua com volume controlado - modo controlado:}

Neste modo, fixa-se a freqüência respiratória, o volume corrente e o fluxo inspiratório. 0 inicio da inspiração (disparo) ocorre de acordo com a freqüência respiratória pré-estabelecida (por exemplo, se a f for de $12 \mathrm{ipm}$, o disparo ocorrerá a cada $5 \mathrm{~s}$ ). 0 disparo ocorre exclusivamente por tempo, ficando o comando sensibilidade desativado (Figura 10).

A transição entre a inspiração e a expiração (ciclagem) ocorre após a liberação do volume

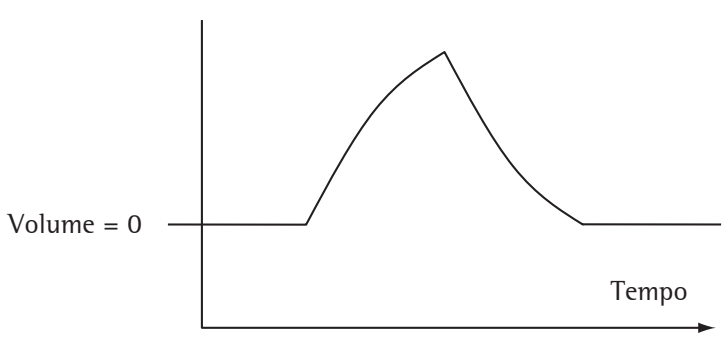

Figura 8 - Curva de volume. 


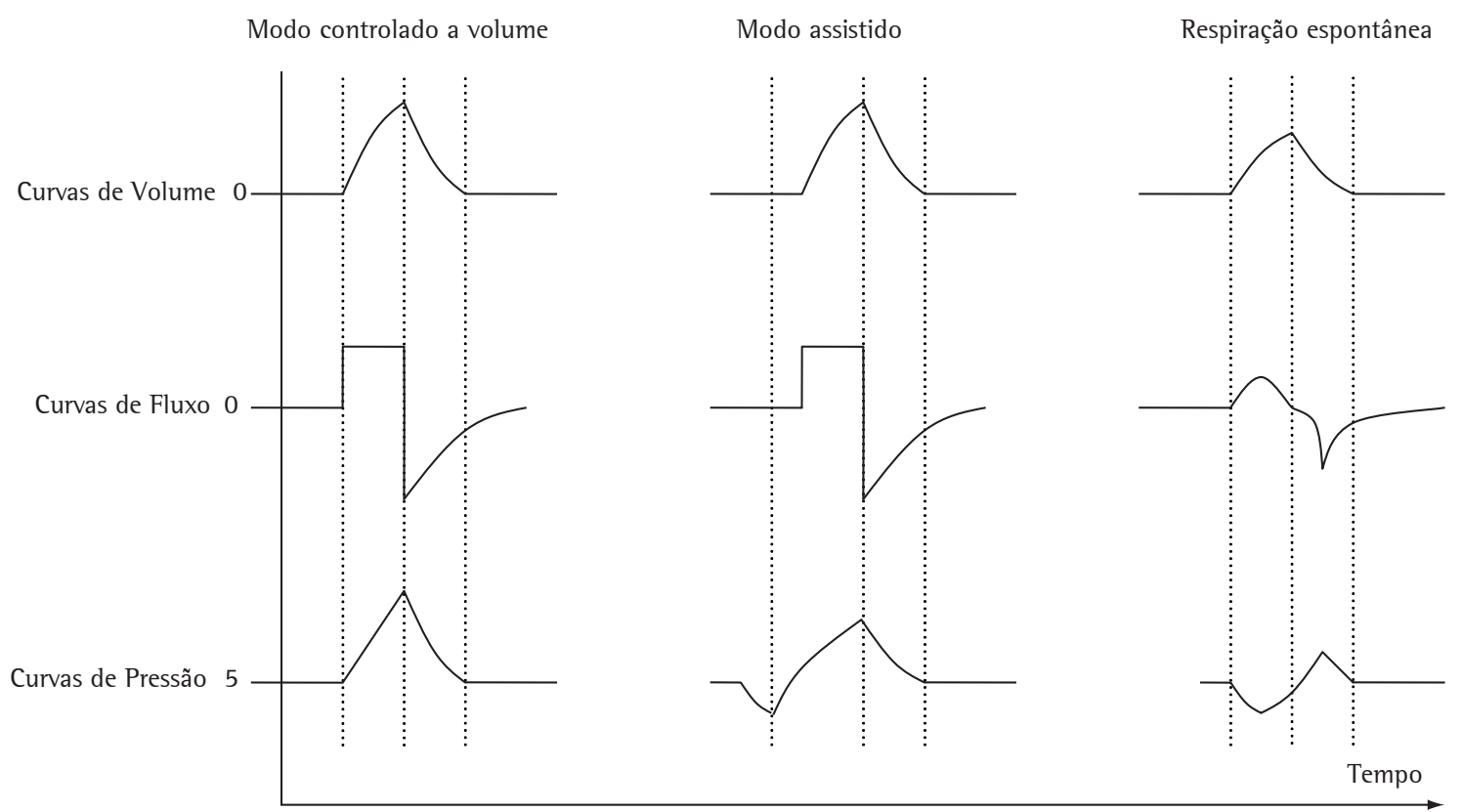

Figura 9 - Associação de curvas.

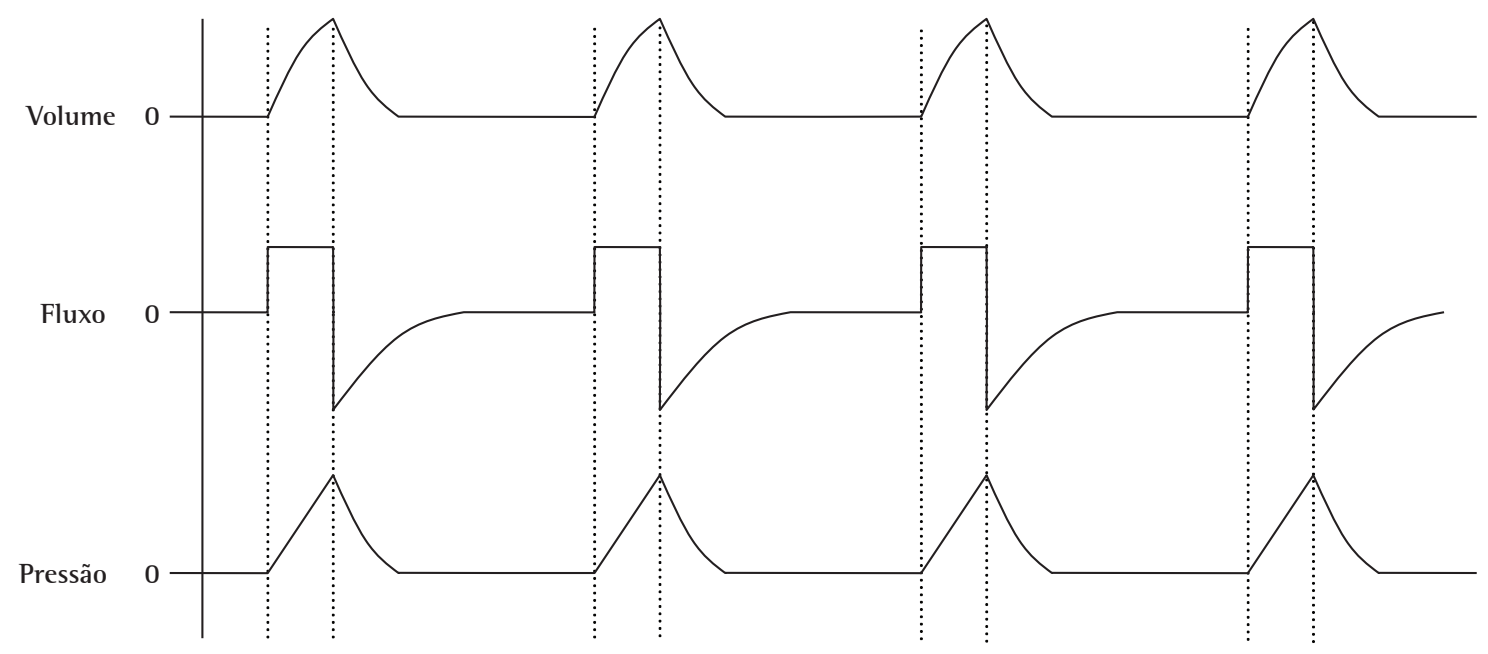

Figura 10 - Ventilação Mecânica Controlada (CMV) limitada a volume.

corrente pré-estabelecido em velocidade determinada pelo fluxo.

\section{Ventilação mandatória contínua com volume controlado - modo assistido-controlado}

Nesta situação, a freqüência respiratória pode variar de acordo com o disparo decorrente do esforço inspiratório do paciente, porém mantêm-se fixos tanto o volume corrente como o fluxo. Caso o paciente não atinja o valor pré-determinado de sensibilidade para disparar o aparelho, este manterá ciclos ventilatórios de acordo com a freqüência respiratória mínima indicada pelo operador (Figura 11).

\section{Ventilação mandatória contínua com pressão controlada - modo controlado}

Neste modo ventilatório, fixa-se a freqüência respiratória, o tempo inspiratório ou a relação inspi- 
ração:expiração (relação Tl/TE), e o limite de pressão inspiratória. 0 disparo continua pré-determinado de acordo com a freqüência respiratória indicada, porém a ciclagem agora acontece de acordo com o tempo inspiratório ou com a relação $\mathrm{Tl} / \mathrm{TE}$ (Figura 12). 0 volume corrente passa a depender da pressão inspiratória pré-estabelecida, das condições de impedância do sistema respiratório e do tempo inspiratório selecionado pelo operador.

\section{Ventilação mandatória contínua com pressão controlada - modo assistido-controlado}

No modo assistido-controlado, os ciclos ocorrem conforme o esforço do paciente ultrapasse a sensibi- lidade. 0 volume corrente obtido passa a depender também desse esforço (Figura 13).

\section{Ventilação mandatória intermitente}

0 ventilador oferece ciclos mandatórios a uma freqüência pré-determinada, porém permite que ciclos espontâneos (ciclos ventilatórios disparados e ciclados pelo paciente) ocorram entre eles. Quando o ventilador permite que o disparo dos ciclos mandatórios ocorra em sincronia com pressão negativa ou fluxo positivo realizado pelo paciente, chamamos este modo de ventilação mandatória intermitente sincronizada (SIMV, do inglês synchronized intermittent mandatory ventilation), que é o modo presente em todos os ventiladores modernos.

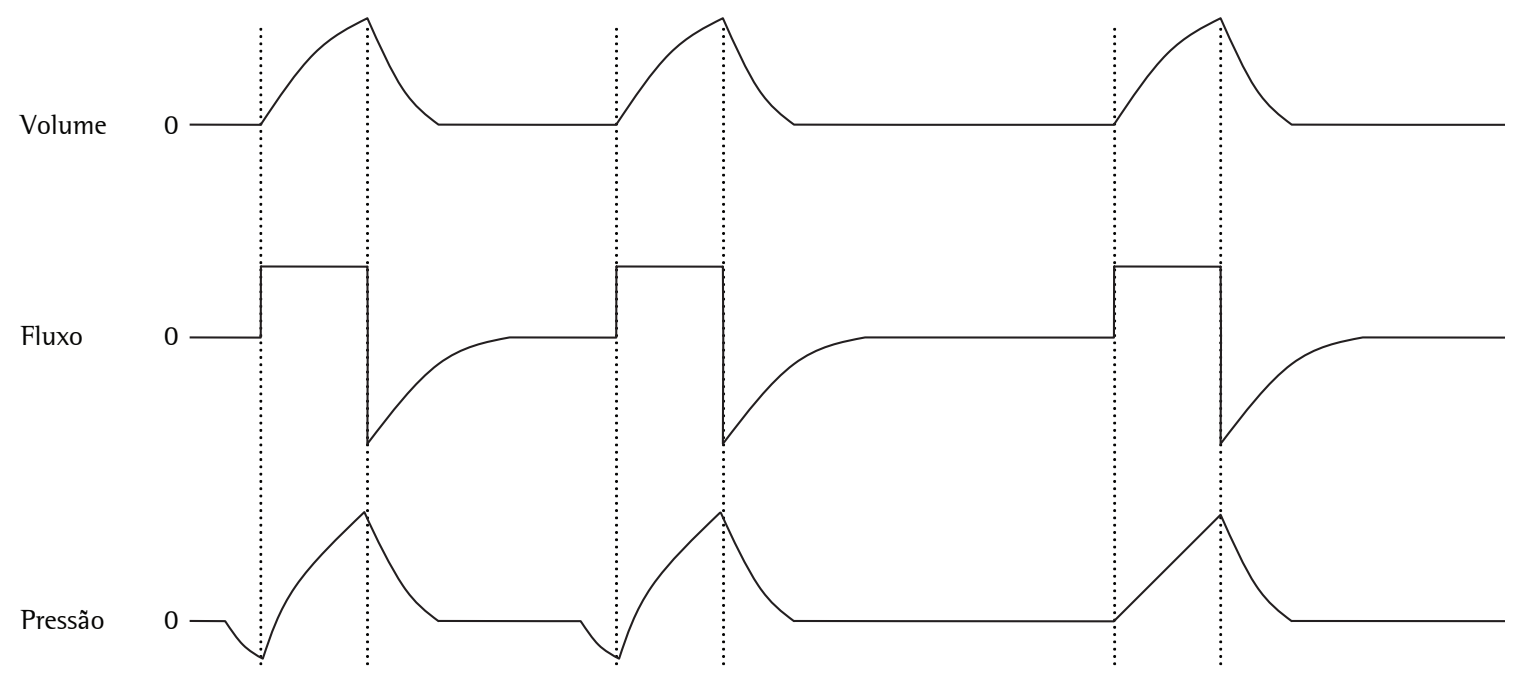

Figura 11 - Ventilação mecânica assistido controlada limitada por volume.

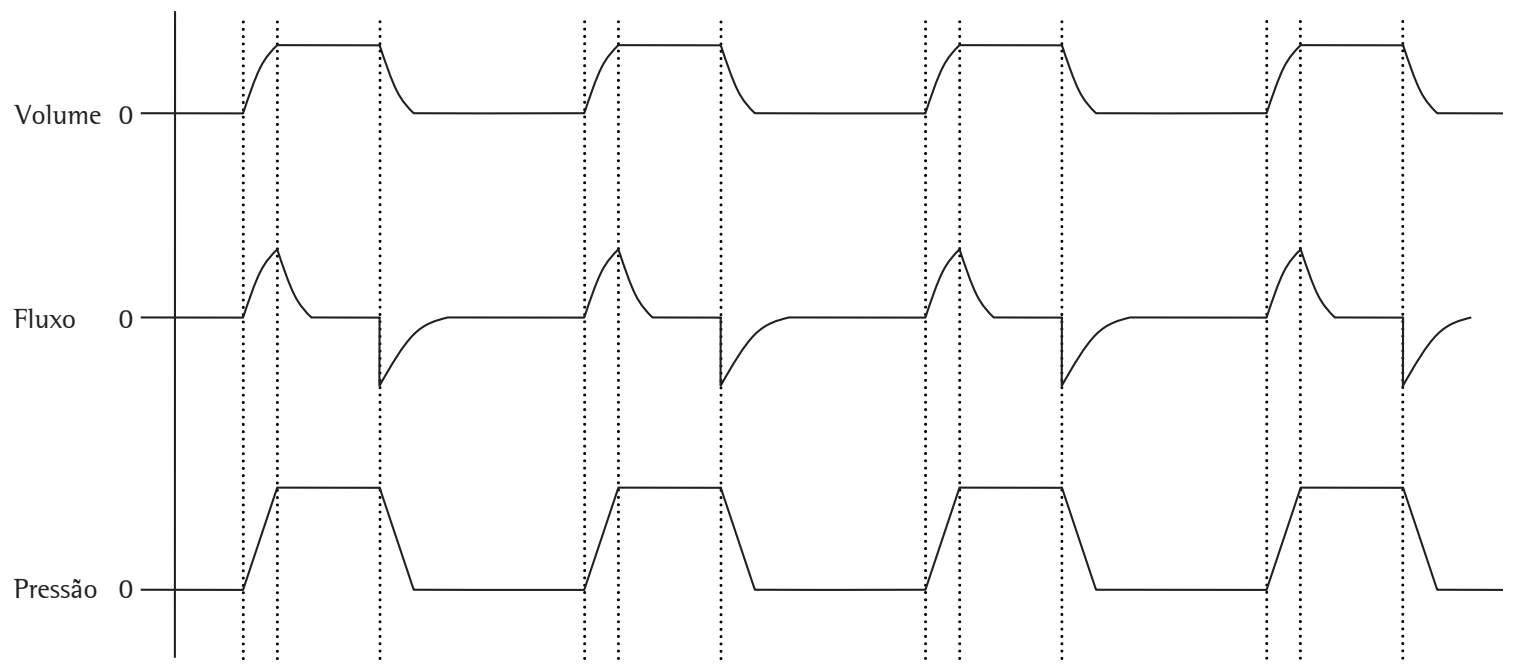

Figura 12 - Ventilação mecânica controlada (CMV) limitada a pressão. 


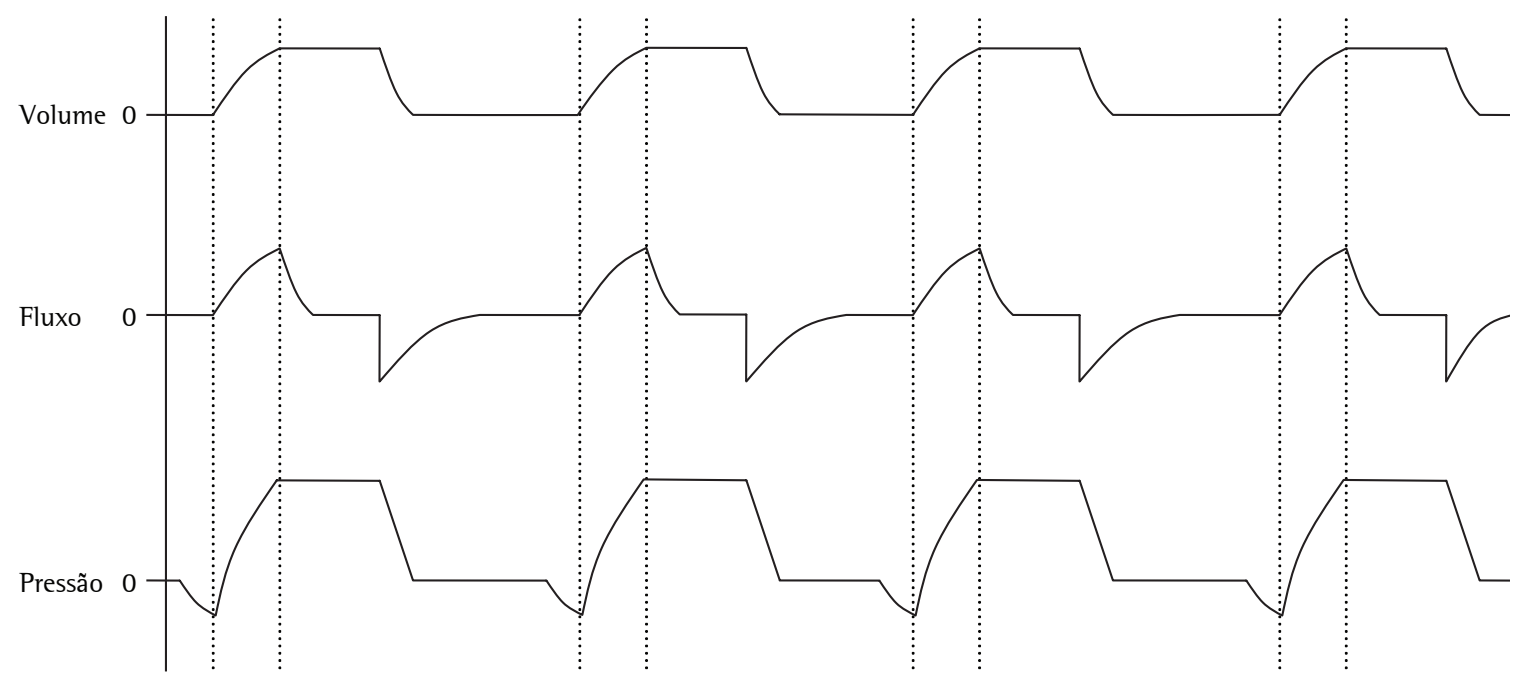

Figura 13 - Ventilação mecânica assistido - controlada limitada por pressão.

Do mesmo modo como ocorre com a ventilação mandatória contínua, nos ventiladores mecânicos mais modernos, a ventilação mandatória intermitente pode ocorrer com volume controlado (os ciclos mandatórios têm como variável de controle o volume, são limitados a fluxo e ciclados a volume) ou com pressão controlada (os ciclos mandatórios têm como variável de controle a pressão, são limitados a pressão e ciclados a tempo).

\section{Ventilação mandatória intermitente sincronizada com volume controlado}

Neste modo, fixa-se a freqüência respiratória, o volume corrente e o fluxo inspiratório, além do critério de sensibilidade para a ocorrência do disparo do ventilador pelo paciente. Esta modalidade ventilatória permite que o ventilador aplique os ciclos mandatórios pré-determinados em sincronia com o esforço inspiratório do paciente. Os ciclos mandatórios ocorrem na janela de tempo pré-determinada (de acordo com a freqüência respiratória do SIMV), porém sincronizados com o disparo do paciente. Se houver uma apnéia, o próximo ciclo será disparado por tempo até que retornem as incursões inspiratórias do paciente (Figura 14).

$\mathrm{Na}$ figura ainda ocorrem três ciclos ventilatórios no período de um minuto, porém, após um período de apnéia no segundo ciclo, ocorre um ciclo disparado a tempo no início do terceiro ciclo. 0 paciente

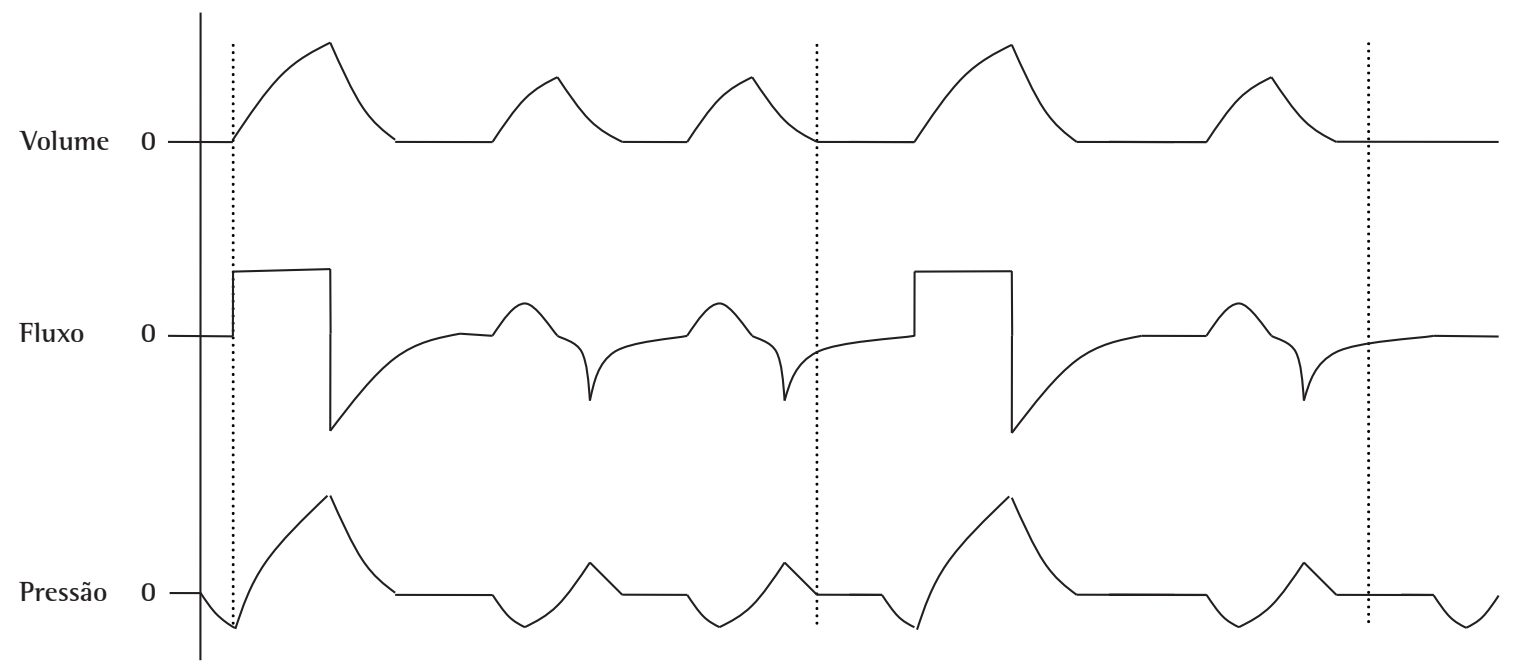

Figura 14 - Ventilação mandatória intermitente sincronizada. 
então retoma a ventilação e dispara um ciclo mandatório ainda no terceiro período (Figura 15).

\section{Ventilação mandatória intermitente sincronizada com pressão controlada}

Semelhante ao modo anterior, com a diferença que os parâmetros definidos pelo operador passam a ser a freqüência respiratória, o tempo inspiratório ou a relação inspiração:expiração (relação Tl:TE), e o limite de pressão inspiratória, além do critério de sensibilidade para a ocorrência do disparo do ventilador pelo paciente.
Ventilação mandatória intermitente sincronizada (com volume controlado ou com pressão controlada) associada a ventilação com pressão de suporte

Existe aqui a combinação das ventilações mandatórias sincronizadas com ventilações espontâneas assistidas através de pressão inspiratória pré-estabelecida (pressão de suporte - Figura 16).

\section{Ventilação espontânea contínua}

Todos os ciclos ventilatórios são espontâneos, ou seja, disparados e ciclados pelo paciente.

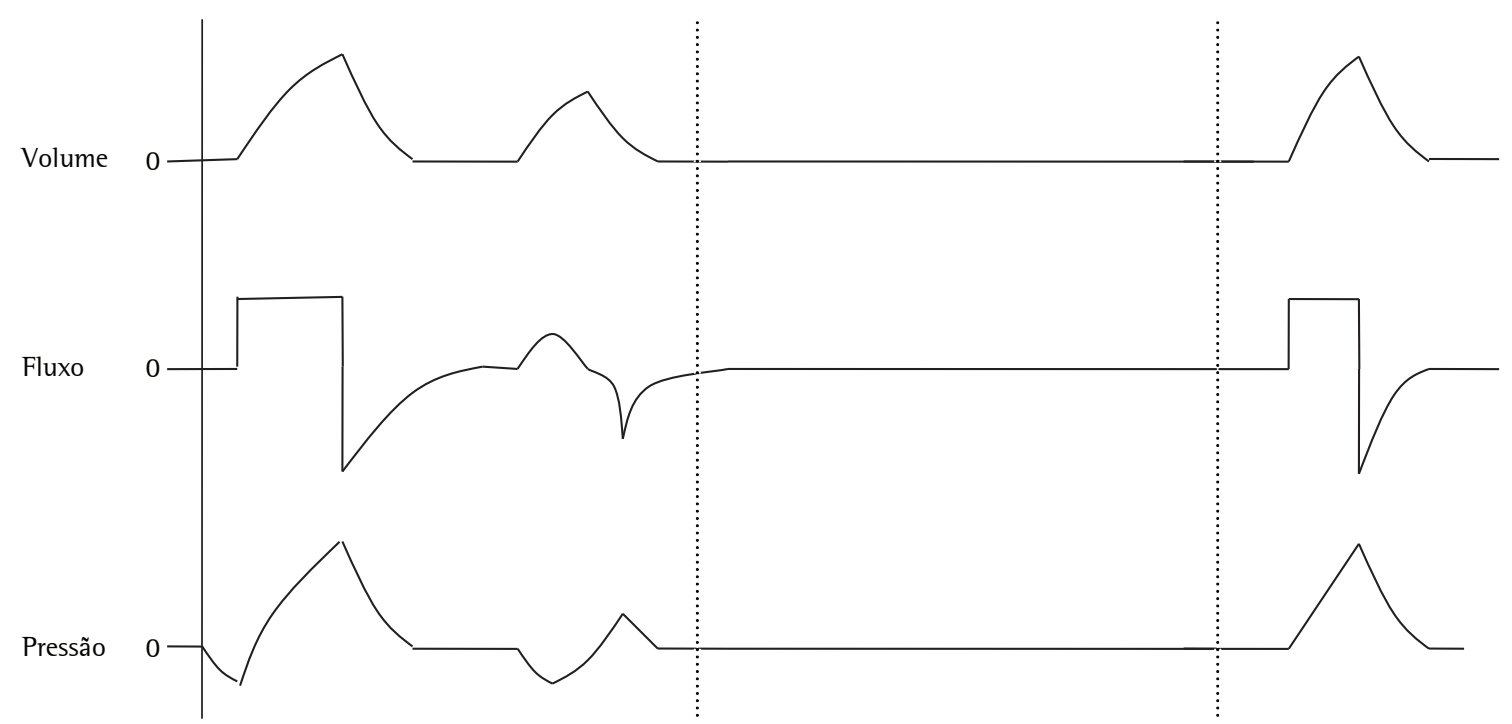

Figura 15 - Ventilação mandatória intermitente sincronizada com apnéia.

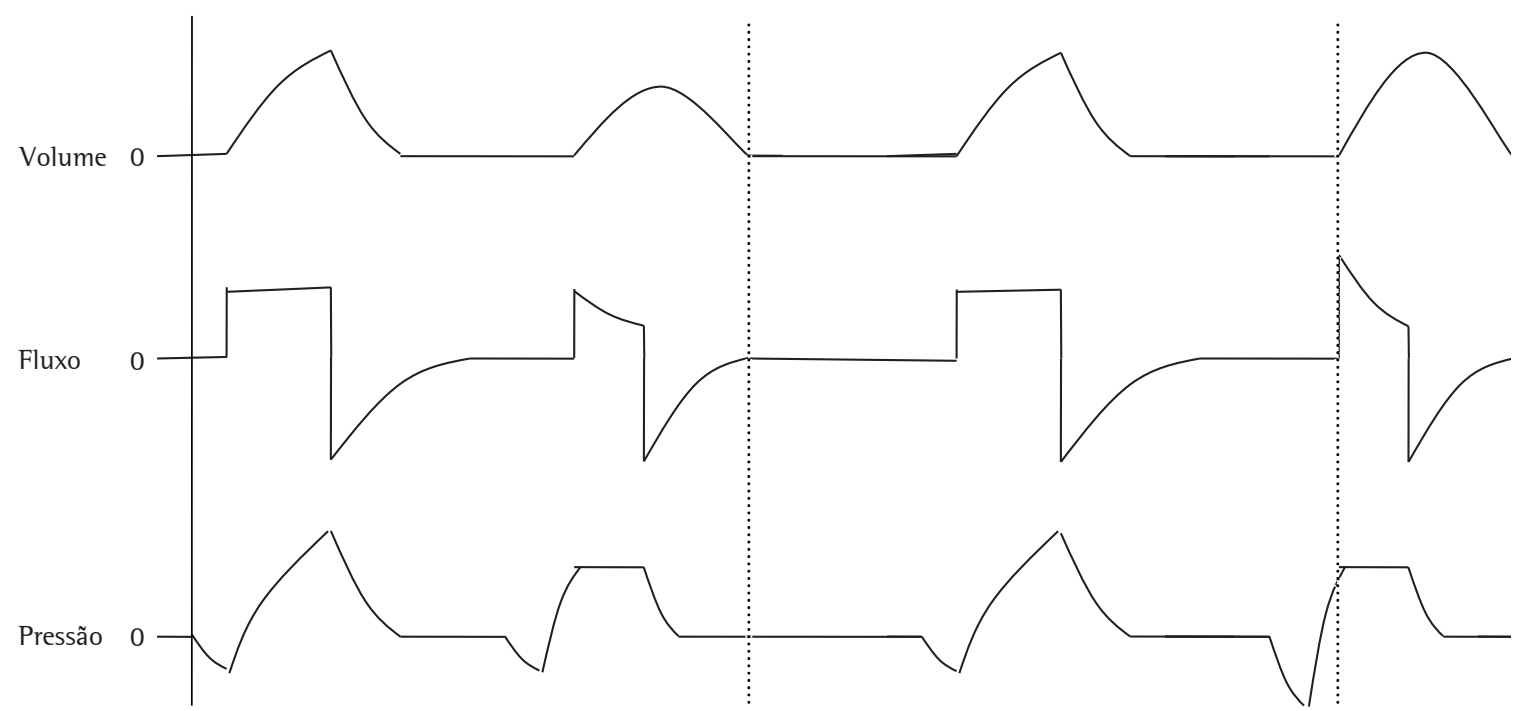

Figura 16 - Ventilação mandatória intermitente sincronizada. 
A ventilação espontânea contínua pode ser assistida pelo ventilador (o ventilador busca alcançar pressões pré-determinadas durante a inspiração ventilação com pressão de suporte - PSV) ou não assistida pelo ventilador (o ventilador mantém uma pressão positiva durante todo o ciclo respiratório, tanto da inspiração como na expiração - pressão positiva nas vias aéreas - CPAP).

\section{Ventilação com pressão de suporte}

Este é um modo de ventilação mecânica espontânea, ou seja, disparado e ciclado pelo paciente, em que o ventilador assiste à ventilação através da manutenção de uma pressão positiva prédeterminada durante a inspiração até que o fluxo inspiratório do paciente reduza-se a um nível crítico, normalmente $25 \%$ do pico de fluxo inspiratório atingido. 1sto permite que o paciente controle a freqüência respiratória e o tempo inspiratório e, dessa forma, o volume de ar inspirado. Assim, o volume corrente depende do esforço inspiratório, da pressão de suporte pré-estabelecida e da mecânica do sistema respiratório. Como desvantagem, este modo funciona apenas quando o paciente apresenta drive respiratório (Figura 17).

\section{Pressão positiva contínua nas vias aéreas}

0 ventilador permite que o paciente ventile espontaneamente, porém fornece uma pressurização contínua tanto na inspiração quanto na expiração. Este é um modo de ventilação espontânea não assistida pelo ventilador. 0 volume corrente depende do esforço inspiratório do paciente e das condições da mecânica respiratória do pulmão e da parede torácica.

\section{Novas modalidades ventilatórias}

Com a introdução e a evolução dos microprocessadores nos ventiladores mecânicos, a possibilidade de sofisticar modos básicos de ventilação mecânica tornou-se enorme, permitindo que novos métodos fossem desenvolvidos baseados em reduzir as limitações presentes e associar métodos básicos de ventilação mecânica. Nem todos os incrementos nos modos ventilatórios são necessariamente avanços e ainda existe pouca evidência quanto à eficácia e segurança de alguns desses novos métodos. Buscaremos aqui listar todos os novos modos disponíveis nos ventiladores comercializados no Brasil, informando sobre seu funcionamento, vantagens e desvantagens demonstradas na literatura.

\section{Modos de duplo controle}

Usualmente, refere-se aos modos ventilatórios como volume-controlado (volume constante, pressão variável) ou pressão-controlada (pressão constante, volume variável), nos quais o ventilador é capaz de manter constante somente uma variável.

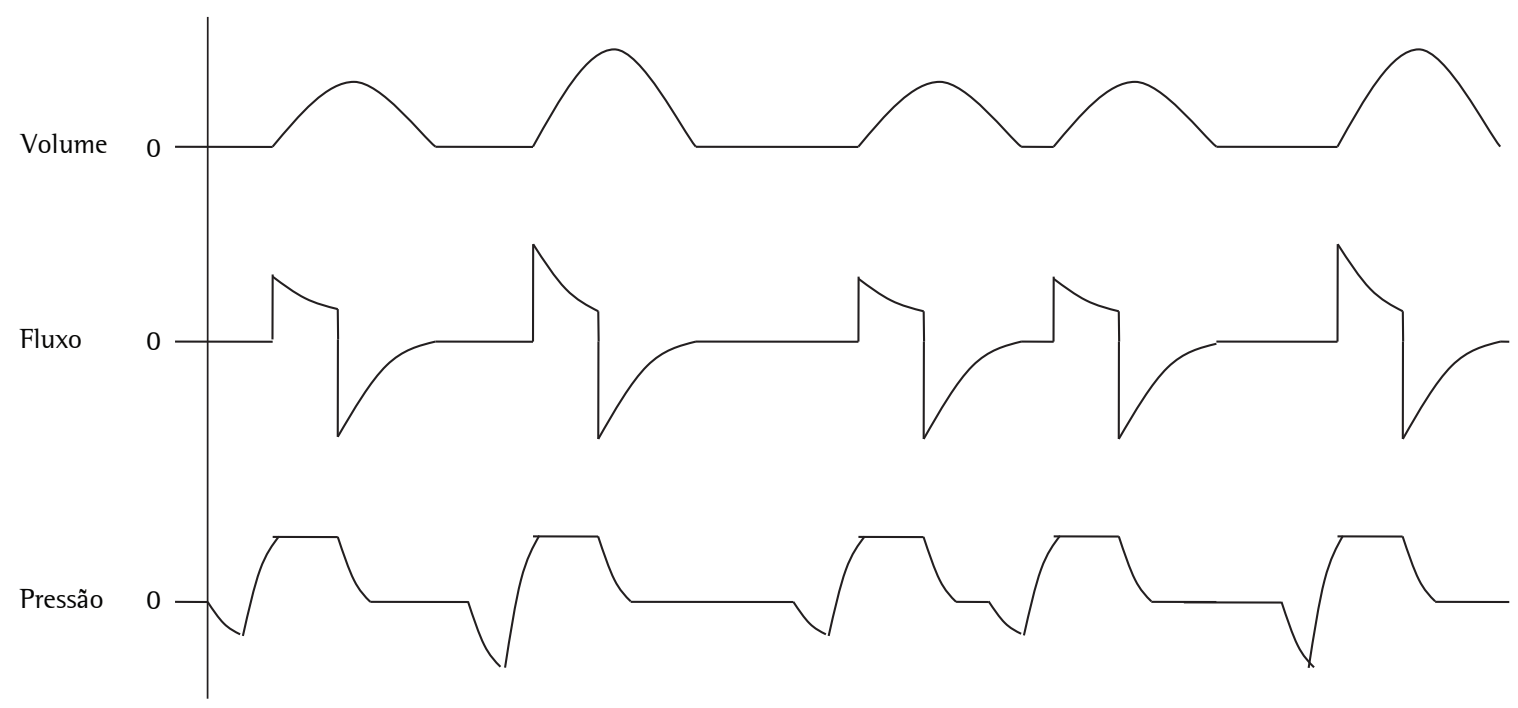

Figura 17 - Ventilação com pressão de suporte (PSV). 


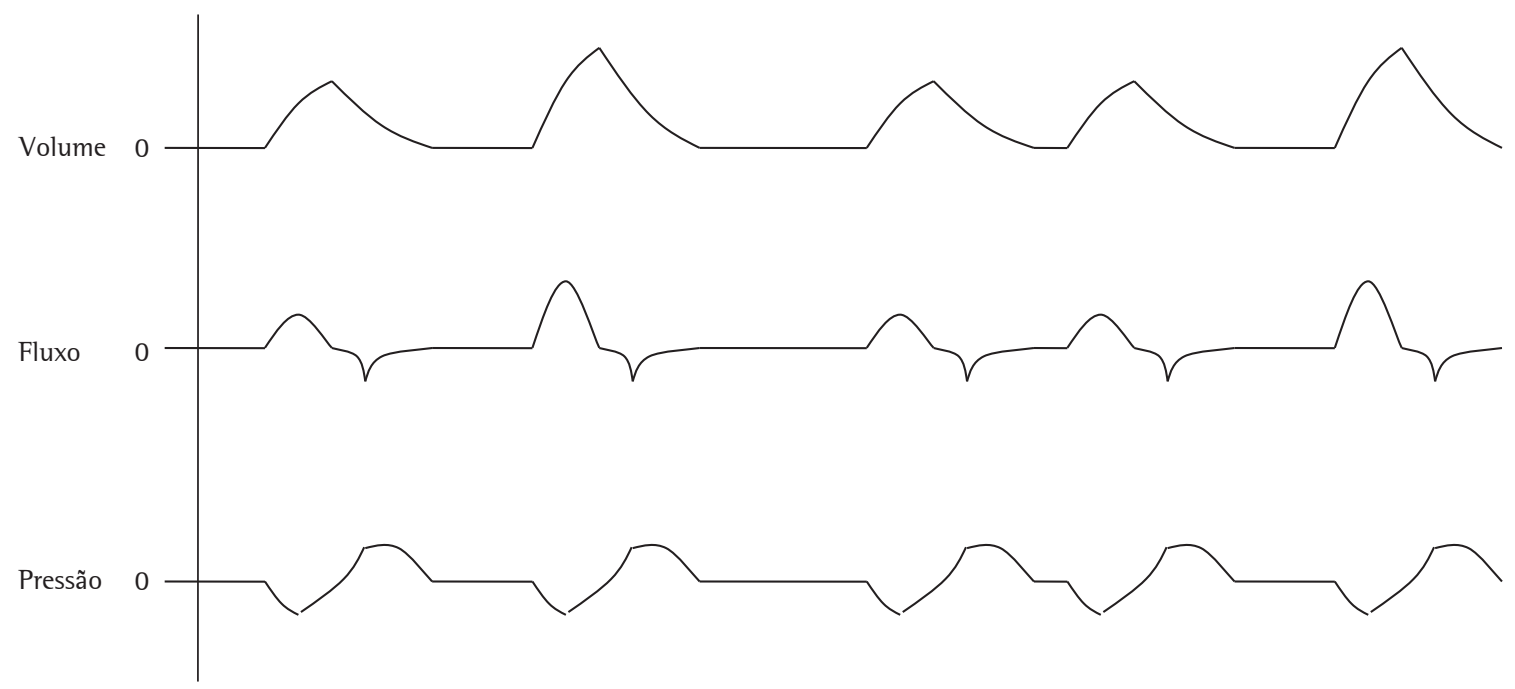

Figura 18 - Pressão positiva contínua nas vias aéreas (CPAP).

Modos desenvolvidos mais recentemente permitem que o ventilador controle uma ou a outra variável, baseado em um mecanismo de feedback de volume corrente. Esses modos são considerados de duplo controle, ou seja, permitem garantir o volume corrente ao mesmo tempo em que o ventilador proporciona ciclos controlados por pressão.

\section{Duplo controle em um único ciclo}

- Pressão de suporte com volume corrente garantido - Volume-Assured Pressure-Support (VAPS

- Bird 8400Sti e Tbird), Pressure Augmentation (PA - Bear 1000)

Nesta forma de ventilação, o ventilador muda do controle a pressão para o controle a volume dentro do mesmo ciclo. Conceitualmente, essa forma ventilatória combina o fluxo inicial alto de uma respiração limitada a pressão com o fluxo constante do modo volume controlado.

Ao escolher este modo ventilatório deve-se indicar a freqüência respiratória, o pico de fluxo, a PEEP, a $\mathrm{FlO}_{2}$, a sensibilidade de disparo, o volume corrente mínimo desejado e a pressão de suporte. 0 ciclo respiratório começa disparado pelo paciente ou por tempo. Após o disparo, o ventilador tenta alcançar a pressão de suporte o mais rápido possível. Esta fase equivale à pressão controlada e associa-se com rápida variação de fluxo reduzindo o trabalho respiratório. Ao alcançar a pressão, o ventilador calcula o volume que foi distribuído na primeira fase da inspiração. Se todo o volume mínimo foi distribuído, a mudança de fase ocorre por ciclagem a fluxo, como no modo pressão de suporte. Se o volume fixado não foi atingido, o fluxo desacelera e alcança o pico de fluxo indicado pelo operador inicialmente e mantém-se constante até que o volume mínimo seja alcançado. Neste momento, a pressão pode ultrapassar a pressão de suporte indicada pelo operador, sendo necessário observar eventuais elevações excessivas de pressão através do alarme da máxima pressão inspiratória.

Neste modo é muito importante indicar a pressão adequada e o fluxo.

- Vantagens: redução do trabalho respiratório mantendo o volume minuto e o volume corrente constante. Melhora da sincronia paciente-ventilador; e

- Desvantagens: podem ocorrer elevados níveis de pressão inspiratória e aumento do tempo inspiratório se os valores do ventilador não forem bem ajustados.

\section{Duplo controle ciclo a ciclo}

0 ventilador opera em pressão de suporte ou em pressão controlada, sendo que o limite de pressão aumenta ou diminui em uma tentativa de manter o volume corrente pré-estabelecido pelo operador.

A) Duplo controle com base na pressão controlada:

- Volume controlado com pressão regulada Pressure-Regulated Volume-Control (PRVC - Servo 300, Servo i), Adaptative Pressure 
Ventilation (APV - Hamilton Galileo), Auto-flow (Evita 4) e Variable Pressure Control (Venturi).

São técnicas de ventilação cicladas a tempo e limitadas a pressão que utilizam o volume corrente como feedback para ajustar continuamente o limite de pressão. Tomando como exemplo o PRVC, o primeiro ciclo respiratório é no modo volume controlado, permitindo ao ventilador calcular a mecânica respiratória. Nos próximos ciclos a ventilação é distribuída com limite de pressão (pressão de platô calculada na primeira ventilação) e ciclada a tempo. A cada ciclo o ventilador ajusta o limite de pressão ( $3 \mathrm{cmH}_{2} \mathrm{O}$ para cima ou para baixo) conforme o volume corrente distribuído no ciclo prévio até alcançar o volume corrente indicado pelo operador. 0 limite de pressão máximo é $5 \mathrm{cmH}_{2} \mathrm{O}$ abaixo do limite de pressão indicado pelo operador.

- Vantagens: permite os volumes minuto e corrente constantes com o controle da pressão, além de reduzir automaticamente o limite de pressão conforme a mecânica do sistema respiratório melhore ou o esforço do paciente aumente; e

- Desvantagens: deve-se ter cuidado ao indicar o volume corrente, pois este será um dos responsáveis pelo pico de pressão alcançado pelo ventilador. Em modos assistidos, conforme aumente a demanda do paciente, a pressão pode se reduzir, reduzindo o suporte ao paciente. A redução da pressão também pode diminuir a pressão média de vias aéreas, reduzindo a oxigenação.

B) Duplo controle com base na pressão de suporte:

- Volume de Suporte (VS) e Pressão de Suporte Variável - Volume Support (VS - Servo 300, Servo i) e Variable Pressure Support (Venturi)

Corresponde ao modo espontâneo das técnicas de duplo controle ciclo a ciclo cicladas a tempo. Nesta técnica, a ventilação é ciclada a fluxo e limitada a pressão, utilizando o volume corrente como feedback para ajustar continuamente o limite de pressão. 0 ventilador inicia os ciclos com uma respiração teste com pico de pressão limitada, medindo-se o volume liberado. A complacência total do sistema é então calculada e nos três ciclos seguintes a pressão inspiratória alcança 75\% do pico de pressão inspiratório calculado para liberar o volume corrente mínimo.

- Vantagens: permite o desmame do paciente gradualmente conforme o esforço do paciente aumente e a mecânica respiratória melhore; e
- Desvantagens: se o nível de pressão aumentar em pacientes obstruídos na tentativa de manter o volume corrente, pode ocorrer o PEEPi. Em casos de hiperpnéia e aumento da demanda do paciente, o suporte de pressão vai diminuir, num efeito inverso ao desejado.

\section{Ventilação Mandatória Minuto (MMV)}

É um modo ventilatório com volume minuto pré-ajustado. 0 paciente pode respirar espontaneamente (com ou sem pressão de suporte) e contribuir para o volume minuto total. A diferença entre o volume minuto pré-ajustado e o volume minuto do paciente é compensada por ciclos mandatórios.

- Vantagem: ajusta automaticamente o suporte ventilatório, evitando reduções do volume minuto decorrentes de alterações da mecânica respiratória ou do esforço do paciente; e

- Desvantagem: se o paciente não realizar ventilações espontâneas funciona como um modo controlado. 0 paciente pode obter o $\dot{\mathrm{V} E}$ ajustado às custas de uma taquipnéia associada a um baixo VT.

\section{Adaptative-Support Ventilation (ASV - Hamilton Galileo)}

Este método ventilatório baseia-se no conceito de Otis. Este sugere que o paciente apresente um VT e uma f que minimiza as cargas elásticas e resistivas mantendo a oxigenação e o equilíbrio ácido-básico. 0 operador indica o peso ideal do paciente (para estimativa do espaço morto), o limite máximo de pressão inspiratória, $\mathrm{PEEP}, \mathrm{FlO}_{2}$, o tempo de retardo, a ciclagem baseada da porcentagem de fluxo do pico de fluxo inicial e a porcentagem de fluxo expiratório distribuído em relação aos $100 \mathrm{~mL} / \mathrm{kg} / \mathrm{min}$ liberados pelo ventilador. Quando conectado ao ventilador, este promove ciclos ventilatórios para medir a complacência, a resistência e a PEEPi. 0 ventilador usa os valores indicados pelo operador e a mecânica respiratória calculada para selecionar a freqüência respiratória, a relação Tl/TE e a pressão limitada para as respirações mandatórias e assistidas, buscando o menor trabalho respiratório.

- Vantagens: permite ao ventilador realizar mudanças automáticas nos parâmetros ventilatórios baseado em mudanças do esforço respiratório e mudanças da mecânica do sistema respiratório; e 
- Desvantagens: apresenta os mesmos problemas dos modos de duplo controle ciclo a ciclo, que são a redução da pressão média de vias aéreas e hipoxemia, a redução da pressão inspiratória quando esta deveria ser aumentada e necessita de adequada indicação da porcentagem de volume minuto para obter um suporte ventilatório eficiente.

\section{Ventilação Proporcional Assistida - Proportional-Assist Ventilation (PAV)}

0 modo PAV foi desenvolvido para aumentar ou reduzir a pressão nas vias aéreas em proporção ao esforço do paciente ao amplificar a proporção de pressão nas vias aéreas pelo suporte em volume e em fluxo inspiratório. Ao contrário de outros modos que oferecem um volume ou pressão pré-selecionados, a PAV determina a quantidade de suporte em relação ao esforço do paciente, assistindo a ventilação com uma proporcionalidade uniforme entre o ventilador e o paciente.

- Vantagens: como é o esforço do paciente (comandado pelo drive central e pela mecânica respiratória) que determina a pressão ventilatória, a PAV pode acompanhar mudanças neste esforço, como num caso de piora ou melhora da insuficiência respiratória. Os estudos têm demonstrado que a PAV produz maior variabilidade de volume corrente e proporciona mais conforto ao paciente em relação à pressão de suporte, porém nenhum desfecho significativo foi diferente até o momento; e

- Desvantagens: necessita que o paciente esteja respirando espontaneamente; ainda há pouca experiência com o método por sua pequena disponibilidade.

\section{Compensação automática do tubo endotraqueal - Automatic Tube Compensation (ATC)}

Compreende um modo que permite compensar a resistência do tubo endotraqueal através da pressão traqueal calculada. A proposta é ultrapassar o trabalho imposto pela via aérea artificial, melhorar a sincronia paciente-ventilador e reduzir o aprisionamento aéreo ao compensar a resistência expiratória. 0 ventilador usa o conhecimento do coeficiente de resistência do tubo endotraqueal ou da traqueostomia e a medida do fluxo para aplicar uma pressão proporcional à resistência durante todo o ciclo respiratório. Durante a expiração também há uma queda de pressão fluxo dependente. 0 operador indica o tipo e o tamanho do tubo e a porcentagem de compensação desejada (10-100\%)

- Vantagens: em alguns casos pode prevenir a hiperinsuflação, a PEEPi e a dissincronia paciente-ventilador.

- Desvantagens: em função da resistência do tubo traqueal in vitro ser menor do que in vivo a compensação pode ser incompleta. Também, quando há secreções ou dobras no tubo, estas não são identificadas e a compensação continua incompleta.

\section{Ventilação por liberação de pressão nas vias aéreas - Airway Pressure-Release Ventilation (APRV)}

No modo APRV, o ventilador trabalha em dois níveis de pressão. A intervalos pré-definidos ocorre alívio transitório do limite superior para o inferior e, posteriormente, também após tempo pré-determinado, restabelece-se a pressão mais alta. Para pacientes que não têm esforços espontâneos, o modo APRV é semelhante ao modo pressão controlada com relação Tl/TE que pode ser ou não invertida, distinguindo-se apenas por permitir ciclos espontâneos nos dois níveis de pressão quando o paciente for capaz de dispará-los.

- Vantagens: pode produzir os efeitos benéficos de elevados níveis pressóricos (melhora da troca gasosa e redução do espaço morto); e

- Desvantagens: o volume corrente é dependente da mecânica respiratória, do tempo de liberação da pressão e do esforço do paciente. Durante a liberação da pressão pode ocorrer derrecrutamento cíclico.

Biphasic intermittent positive airway pressure (BIPAP) é uma modificação do APRV (ciclos espontâneos possíveis em dois níveis de pressão basal), diferindo deste pela relação Tl:TE, que é normal, e pela possibilidade de sincronia parcial com o esforço inspiratório do paciente, permitindo que o tempo inspiratório e expiratório seja reduzido até $25 \%$ baseado no esforço inspiratório do paciente. Sem respiração espontânea, o BIPAP é semelhante ao modo pressão controlada.

Apresenta vantagens e desvantagens semelhantes ao APRV. BIPAP (também chamado PCV+) é dispo- 
nível no Drager Evita 4. É também disponível como BiLevel no Puritan-Bennett 840. BIPAP não deve ser confundido com BiPAP (nome comercial de um ventilador portátil para ventilação não invasiva).

Quadro 1 - Modos ventilatórios.

\begin{tabular}{|c|c|c|c|c|c|c|c|}
\hline \multirow{2}{*}{$\begin{array}{c}\text { Variável de } \\
\text { controle }\end{array}$} & \multicolumn{3}{|c|}{ Ciclo mandatório } & \multicolumn{3}{|c|}{ Ciclo espontâneo } & \multirow[t]{2}{*}{ Modo ventilatório } \\
\hline & Disparo & Limite & Ciclagem & Disparo & Limite & Ciclagem & \\
\hline \multirow[t]{3}{*}{ Volume } & Tempo & Fluxo & Volume & - & - & - & $\begin{array}{l}\text { Ventilação manda- } \\
\text { tória contínua com } \\
\text { volume controlado } \\
\text { - modo controlado }\end{array}$ \\
\hline & $\begin{array}{l}\text { Tempo, } \\
\text { pressão ou } \\
\text { fluxo }\end{array}$ & Fluxo & Volume & - & - & - & $\begin{array}{l}\text { Ventilação manda- } \\
\text { tória contínua } \\
\text { com volume } \\
\text { controlado - modo } \\
\text { assistido-controlado }\end{array}$ \\
\hline & $\begin{array}{l}\text { Tempo, } \\
\text { pressão ou } \\
\text { fluxo }\end{array}$ & Fluxo & Volume & $\begin{array}{l}\text { Pressão ou } \\
\text { fluxo }\end{array}$ & Pressão & Pressão & $\begin{array}{l}\text { Ventilação manda- } \\
\text { tória intermitente } \\
\text { com volume } \\
\text { controlado }\end{array}$ \\
\hline \multirow[t]{5}{*}{ Pressão } & Tempo & Pressão & Tempo & - & - & - & $\begin{array}{l}\text { Ventilação manda- } \\
\text { tória contínua com } \\
\text { pressão controlada } \\
\text { - modo controlado }\end{array}$ \\
\hline & $\begin{array}{l}\text { Tempo, } \\
\text { pressão ou } \\
\text { fluxo }\end{array}$ & Pressão & Tempo & - & - & - & $\begin{array}{l}\text { Ventilação manda- } \\
\text { tória contínua } \\
\text { com pressão } \\
\text { controlada - modo } \\
\text { assistido-controlado }\end{array}$ \\
\hline & $\begin{array}{l}\text { Tempo, } \\
\text { pressão ou } \\
\text { fluxo }\end{array}$ & Pressão & Tempo & $\begin{array}{l}\text { Pressão ou } \\
\text { fluxo }\end{array}$ & Pressão & Pressão & $\begin{array}{l}\text { Ventilação } \\
\text { mandatória } \\
\text { intermitente com } \\
\text { pressão-controlada }\end{array}$ \\
\hline & - & - & - & $\begin{array}{l}\text { Pressão ou } \\
\text { fluxo }\end{array}$ & Pressão & Fluxo & $\begin{array}{l}\text { PSV = pressure- } \\
\text { support ventilation } \\
\text { (pressão de suporte) }\end{array}$ \\
\hline & - & - & - & $\begin{array}{l}\text { Pressão ou } \\
\text { fluxo }\end{array}$ & Pressão & $\begin{array}{l}\text { Pressão ou } \\
\text { fluxo }\end{array}$ & $\begin{array}{l}\text { CPAP = continuous } \\
\text { positive airway } \\
\text { pressure (pressão } \\
\text { positiva contínua } \\
\text { nas vias aéreas) }\end{array}$ \\
\hline
\end{tabular}


Quadro 2 - Modos ventilatórios disponíveis em ventiladores mecânicos selecionados.

\begin{tabular}{|c|c|c|c|c|c|c|c|c|c|c|c|c|}
\hline & VMC & VMl & CPAP & PSV & MMV & $\begin{array}{c}\text { VAPS ou } \\
\text { PA }\end{array}$ & $\begin{array}{c}\text { PRVC, APV, } \\
\text { Autoflow } \\
\text { ou VPC }\end{array}$ & $\begin{array}{l}\text { VS ou } \\
\text { VPS }\end{array}$ & ASV & $\begin{array}{l}\text { ATC } \\
\text { ou } \\
\text { TRC }\end{array}$ & $\begin{array}{c}\text { APRV, } \\
\text { PCV+ ou } \\
\text { Bilevel }\end{array}$ & $\begin{array}{l}\text { PAV, } \\
\text { PAV } \\
\text { Plus }\end{array}$ \\
\hline Bear 5 & V & V & + & + & + & & & & & & & \\
\hline Bird 6400ST & V & V & + & + & & & & & & & & \\
\hline Bird 8400STi & $\mathrm{V}, \mathrm{P}$ & $\mathrm{V}, \mathrm{P}$ & + & + & & + (VAPS) & & & & & & \\
\hline Dixtal DX3020 & $\mathrm{V}, \mathrm{P}$ & $\mathrm{V}, \mathrm{P}$ & + & + & + & + (VAPS) & & & & & & \\
\hline Drager Savina & $\mathrm{V}, \mathrm{P}$ & $\mathrm{V}, \mathrm{P}$ & + & + & & & $\begin{array}{c}+ \\
\text { (Autoflow) }\end{array}$ & & & & $+(\mathrm{PCV}+)$ & \\
\hline $\begin{array}{l}\text { Drager Evita } 2 \\
\text { Dura }\end{array}$ & $\mathrm{V}, \mathrm{P}$ & $\mathrm{V}, \mathrm{P}$ & + & + & + & & $\begin{array}{c}+ \\
\text { (Autoflow) }\end{array}$ & & & + & $\begin{array}{c}+(\mathrm{APRV}, \\
\text { PCV+) }\end{array}$ & \\
\hline Drager Evita 4 & $\mathrm{~V}, \mathrm{P}$ & $\mathrm{V}, \mathrm{P}$ & + & + & + & & $\begin{array}{c}+ \\
\text { (Autoflow) }\end{array}$ & & & + & $\begin{array}{c}+(\mathrm{APRV}, \\
\text { PCV+) }\end{array}$ & \\
\hline $\begin{array}{l}\text { Drager Evita } \\
\text { XL }\end{array}$ & $\mathrm{V}, \mathrm{P}$ & $\mathrm{V}, \mathrm{P}$ & + & + & + & & $\begin{array}{c}+ \\
\text { (Autoflow) }\end{array}$ & & & + & $\begin{array}{c}+(\mathrm{APRV}, \\
\text { PCV+) }\end{array}$ & \\
\hline GE Centiva & $\mathrm{V}, \mathrm{P}$ & $\mathrm{V}, \mathrm{P}$ & + & + & & & & & & + & & \\
\hline $\begin{array}{l}\text { GE Centiva } \\
\text { Plus }\end{array}$ & $\mathrm{V}, \mathrm{P}$ & $\mathrm{V}, \mathrm{P}$ & + & + & & & & & & + & & \\
\hline $\begin{array}{l}\text { GE Engstrom } \\
\text { Carestation }\end{array}$ & $\mathrm{V}, \mathrm{P}$ & $\mathrm{V}, \mathrm{P}$ & + & + & & & $\begin{array}{c}+ \\
(\mathrm{PRVC})\end{array}$ & & & + & $\begin{array}{c}+ \text { (APRV, } \\
\text { Bilevel) }\end{array}$ & \\
\hline $\begin{array}{l}\text { Hamilton } \\
\text { Amadeus }\end{array}$ & V & V & + & + & & & & & & & & \\
\hline $\begin{array}{l}\text { Hamilton } \\
\text { Veolar }\end{array}$ & $\mathrm{V}, \mathrm{P}$ & $\mathrm{V}, \mathrm{P}$ & + & + & + & & & & & & & \\
\hline $\begin{array}{l}\text { Hamilton } \\
\text { Raphael Basic }\end{array}$ & $\mathrm{V}, \mathrm{P}$ & $\mathrm{V}, \mathrm{P}$ & + & + & & & & & & & & \\
\hline $\begin{array}{l}\text { Hamilton } \\
\text { Raphael Silver }\end{array}$ & $\mathrm{V}, \mathrm{P}$ & $\mathrm{V}, \mathrm{P}$ & + & + & & & & & + & $\begin{array}{c}+ \\
(\mathrm{TRC})\end{array}$ & $+(\mathrm{APRV})$ & \\
\hline $\begin{array}{l}\text { Hamilton } \\
\text { Raphael Color }\end{array}$ & $\mathrm{V}, \mathrm{P}$ & $\mathrm{V}, \mathrm{P}$ & + & + & & & & & + & $\begin{array}{c}+ \\
(\mathrm{TRC})\end{array}$ & + (APRV) & \\
\hline $\begin{array}{l}\text { Hamilton } \\
\text { Galileo Classic }\end{array}$ & $\mathrm{V}, \mathrm{P}$ & $\mathrm{V}, \mathrm{P}$ & + & + & & & $\begin{array}{c}+ \\
(\mathrm{APV})\end{array}$ & & + & & $+(\mathrm{APRV})$ & \\
\hline $\begin{array}{l}\text { Hamilton } \\
\text { Galileo Gold }\end{array}$ & $\mathrm{V}, \mathrm{P}$ & $\mathrm{V}, \mathrm{P}$ & + & + & & & $\begin{array}{c}+ \\
(\mathrm{APV})\end{array}$ & & + & & $+(\mathrm{APRV})$ & \\
\hline $\begin{array}{l}\text { Intermed } \\
\text { Inter } 5\end{array}$ & $\mathrm{~V}, \mathrm{P}$ & $\mathrm{V}, \mathrm{P}$ & + & + & & & & & & & & \\
\hline $\begin{array}{l}\text { Intermed } \\
\text { Inter } 5 \text { Plus }\end{array}$ & $\mathrm{V}, \mathrm{P}$ & $\mathrm{V}, \mathrm{P}$ & + & + & & & & & & & & \\
\hline $\begin{array}{l}\text { Intermed } \\
\text { Interplus }\end{array}$ & $\mathrm{V}, \mathrm{P}$ & $\mathrm{V}, \mathrm{P}$ & + & + & & + (VAPS) & & & & & & \\
\hline $\begin{array}{l}\text { Maquet } \\
\text { Servo s }\end{array}$ & $\mathrm{V}, \mathrm{P}$ & $\mathrm{V}, \mathrm{P}$ & + & + & & & & & & & & \\
\hline $\begin{array}{l}\text { Maquet Servo i } \\
\text { Universal }\end{array}$ & $\mathrm{V}, \mathrm{P}$ & $\mathrm{V}, \mathrm{P}$ & + & + & & & $\begin{array}{c}+ \\
(\mathrm{PRVC})\end{array}$ & $\begin{array}{c}+ \\
\text { (VS) }\end{array}$ & & & & \\
\hline $\begin{array}{l}\text { Puritan } \\
\text { Bennett } 7200\end{array}$ & $\mathrm{~V}, \mathrm{P}$ & $\mathrm{V}, \mathrm{P}$ & + & + & & & & & & & & \\
\hline $\begin{array}{l}\text { Puritan } \\
\text { Bennett } 760\end{array}$ & $\mathrm{~V}, \mathrm{P}$ & $\mathrm{V}, \mathrm{P}$ & + & + & & & & & & & & \\
\hline $\begin{array}{l}\text { Puritan } \\
\text { Bennett } 840\end{array}$ & $\mathrm{~V}, \mathrm{P}$ & $\mathrm{V}, \mathrm{P}$ & + & + & & & & & & $\begin{array}{c}+ \\
(\mathrm{ATC})\end{array}$ & $\begin{array}{c}+ \text { (APRV, } \\
\text { Bilevel) }\end{array}$ & $\begin{array}{c}+ \\
\text { (PAV } \\
\text { Plus) } \\
\end{array}$ \\
\hline
\end{tabular}


Quadro 2 - Continuação.

\begin{tabular}{|c|c|c|c|c|c|c|c|c|c|c|c|}
\hline & VMC & VMl & CPAP & PSV & MMV & $\begin{array}{c}\text { VAPS ou } \\
\text { PA }\end{array}$ & $\begin{array}{c}\text { PRVC, APV, } \\
\text { Autoflow } \\
\text { ou VPC }\end{array}$ & $\begin{array}{l}\text { VS ou ASV } \\
\text { VPS }\end{array}$ & $\begin{array}{l}\text { ATC } \\
\text { ou } \\
\text { TRC }\end{array}$ & $\begin{array}{c}\text { APRV, } \\
\text { PCV+ ou } \\
\text { Bilevel }\end{array}$ & $\begin{array}{l}\text { PAV, } \\
\text { PAV } \\
\text { Plus }\end{array}$ \\
\hline $\begin{array}{l}\text { Newport E100 } \\
\mathrm{m}\end{array}$ & $\mathrm{V}, \mathrm{P}$ & $\mathrm{V}, \mathrm{P}$ & + & + & & & & & & & \\
\hline Newport E360 & $\mathrm{V}, \mathrm{P}$ & $\mathrm{V}, \mathrm{P}$ & + & + & & & & & & + (APRV) & \\
\hline Newport E500 & $\mathrm{V}, \mathrm{P}$ & $\mathrm{V}, \mathrm{P}$ & + & + & & & & & & + (APRV) & \\
\hline $\begin{array}{l}\text { Respironics } \\
\text { BiPAP S/T-D } \\
30\end{array}$ & & & + & & & & & & & & \\
\hline $\begin{array}{l}\text { Respironics } \\
\text { BiPAP Vision }\end{array}$ & & & + & & & & & & & & $\begin{array}{c}+ \\
(\mathrm{PAV})\end{array}$ \\
\hline $\begin{array}{l}\text { Respironics } \\
\text { Espirit }\end{array}$ & $\mathrm{V}, \mathrm{P}$ & $\mathrm{V}, \mathrm{P}$ & + & + & & & $\begin{array}{c}+ \\
\text { (Autoflow) }\end{array}$ & & & & \\
\hline $\begin{array}{l}\text { Siemens Servo } \\
900 \mathrm{E}\end{array}$ & V & V & + & + & & & & & & & \\
\hline $\begin{array}{l}\text { Siemens Servo } \\
900 \mathrm{C}\end{array}$ & $\mathrm{V}, \mathrm{P}$ & $\mathrm{V}, \mathrm{P}$ & + & + & & & & & & & \\
\hline Taema Horus 4 & $\mathrm{~V}, \mathrm{P}$ & $\mathrm{V}, \mathrm{P}$ & + & + & & & $\begin{array}{c}+ \\
\text { (PRVC) }\end{array}$ & & & $+(\mathrm{APRV})$ & \\
\hline $\begin{array}{l}\text { Taema Horus } \\
\text { Extend }\end{array}$ & $\mathrm{V}, \mathrm{P}$ & $\mathrm{V}, \mathrm{P}$ & + & + & & & $\begin{array}{c}+ \\
(\mathrm{PRVC})\end{array}$ & & & $+(\mathrm{APRV})$ & \\
\hline $\begin{array}{l}\text { Takaoka } \\
\text { ServoVentilator } \\
\text { Smart }\end{array}$ & $\mathrm{V}, \mathrm{P}$ & $\mathrm{V}, \mathrm{P}$ & + & + & & & & & $\begin{array}{c}+ \\
(\mathrm{ATC})\end{array}$ & & \\
\hline $\begin{array}{l}\text { Takaoka } \\
\text { ServoVentilator } \\
\text { Carmel }\end{array}$ & $\mathrm{V}, \mathrm{P}$ & $\mathrm{V}, \mathrm{P}$ & + & + & & & & & & & \\
\hline $\begin{array}{l}\text { Takaoka } \\
\text { ServoVentilator } \\
\text { Color }\end{array}$ & $\mathrm{V}, \mathrm{P}$ & $\mathrm{V}, \mathrm{P}$ & + & + & + & & & & $\begin{array}{c}+ \\
(\mathrm{ATC})\end{array}$ & & \\
\hline Vyasis Vela & $\mathrm{V}, \mathrm{P}$ & $\mathrm{V}, \mathrm{P}$ & + & + & & & $\begin{array}{c}+ \\
\text { (PRVC) }\end{array}$ & + & & + (APRV) & \\
\hline Vyasis Avea & $\mathrm{V}, \mathrm{P}$ & $\mathrm{V}, \mathrm{P}$ & + & + & + & & $\begin{array}{c}+ \\
\text { (PRVC) }\end{array}$ & & $\begin{array}{c}+ \\
(\mathrm{ATC})\end{array}$ & + (APRV) & \\
\hline
\end{tabular}

Abreviaturas: $\mathrm{V}$ = volume controlado; $\mathrm{P}$ = pressão controlada; $\mathrm{VMC}=$ ventilação mandatória contínua; $\mathrm{VMl}=$ ventilação mandatória intermitente; $\mathrm{CPAP}=$ continuous positive airway pressure (pressão positiva contínua nas vias aéreas); PSV = pressure support ventilation (pressão de suporte); MMV = mandatory minute ventilation (ventilação mandatória minuto); VAPS = volume-assured pressure-support (pressão de suporte com volume corrente garantido); $\mathrm{PA}=$ pressure augmentation; $\mathrm{PRVC}=$ pressure-regulated volume control (volume controlado com pressão regulada); APV = adaptative pressure ventilation; VPC = variable pressure control; VS = volume support (volume de suporte); VPS = variable pressure support, ASV $=$ adaptative-support ventilation; ATC $=$ automatic tube compensation (compensação automática de tubo endotraqueal); TRC = tube resistence compensation; APRV = airway pressure-release ventilation (ventilação com liberação de pressão nas vias aéreas); PAV = proportional-assist ventilation (ventilação assistida proporcional); PAV Plus= proportional-assist ventilation Plus (ventilação assistida proporcional com mecânica respiratória automática). 